\title{
Use and Switching of Biologic Therapy in Patients with Non-Radiographic Axial Spondyloarthritis: A Patient and Provider Survey in the United States
}

\author{
Atul Deodhar - David Sandoval - Elizabeth Holdsworth • \\ Nicola Booth · Theresa Hunter
}

Received: March 19, 2020 / Published online: April 23, 2020

(C) The Author(s) 2020

\section{ABSTRACT}

Introduction: The Food and Drug Administration (FDA) approved certolizumab-pegol, the first biologic for the treatment of non-radiographic axial spondyloarthritis (nr-axSpA), for use in the United States (US) in March of 2019. The objective of this study was to investigate biologic use and reasons for switching therapy among patients with nr-axSpA in the US.

Methods: This was a real-world, cross-sectional study of rheumatologists conducted in the US. Data were collected from June to August of 2018 via rheumatologist-completed patient record forms. Data from patients who had a rheumatologist-confirmed diagnosis of nr-axSpA were included in the study. Rheumatologists provided information on current medication use and reasons for switching biologics.

Results: Eighty-eight rheumatologists collected data on 495 nr-axSpA patients. Over half of nr-

Digital Features To view digital features for this article go to: https://doi.org/10.6084/m9.figshare.12123918.

A. Deodhar

Oregon Health and Science University, Portland, OR, USA

D. Sandoval · T. Hunter $(\bowtie)$

Eli Lilly and Company, Indianapolis, IN, USA

e-mail: hunter_theresa_marie@lilly.com

E. Holdsworth · N. Booth

Adelphi Real World, Bollington, UK
axSpA patients were male (53.3\%), with a mean age of 44.2 years, and $69.8 \%$ of patients reported working full-time. Of the $495 \mathrm{nr}$-axSpA patients, $48.1 \%$ were receiving a biologic and no conventional synthetic disease-modifying antirheumatic drug (csDMARD), 18.4\% csDMARD (no biologic), 18.2\% non-steroidal anti-inflammatory drug (NSAIDs)/COX-2 (no biologic or csDMARD), $11.5 \%$ a biologic and a csDMARD, $2.0 \%$ were receiving no therapy, and $1.8 \%$ other therapy (no biologic, csDMARD, or NSAID/ COX-2). Of 295 patients receiving a biologic, $77.8 \%$ were receiving their first, $13.8 \%$ their second, and $8.3 \%$ their third or more biologic. Of $74 \mathrm{nr}$-axSpA patients who switched from a previous biologic to their current biologic, rheumatologists reported that $51.4 \%$ switched due to condition worsening, $48.6 \%$ had a loss of response over time, $27.0 \%$ switched due to a lack of pain alleviation, and $25.7 \%$ of patients switched because remission was not induced.

Conclusions: This study suggests that around $60 \%$ of nr-axSpA patients were receiving biologic therapy prior to the approval of certolizumab pegol. Switching of biologics is frequent in nr-axSpA patients and is usually due to lack of efficacy, loss or response, and effort to accomplish remission.

Keywords: Biologic therapy; Non-radiographic axial spondyloarthritis; Treatment patterns 


\section{Key Summary Points}

\section{Why carry out this study?}

The purpose of this study is to investigate biologic use and reasons for switching therapy among patients with nonradiographic axial spondyloarthritis (nraxSpA) in the United States.

\section{What was learned from the study?}

This study suggests that around $60 \%$ of nraxSpA patients in the United States were receiving biologic therapy prior to the approval of certolizumab-pegol.

Switching of biologics is frequent in nraxSpA patients and is usually due to lack of efficacy, loss or response, and effort to accomplish remission.

\section{INTRODUCTION}

Axial spondyloarthritis (axSpA) is an immunemediated chronic inflammatory disease which includes two subtypes within the same disease spectrum. Patients with axSpA can be classified as ankylosing spondylitis (AS) or radiographic axSpA ( $\mathrm{r}-\mathrm{axSpA})$ based upon the mNY criteria for AS [1] or the Assessment of SpondyloArthritis international Society (ASAS) criteria for r-axSpA [2]. In addition, patients can be classified as non-radiographic axial spondyloarthritis (nr-axSpA) based on ASAS criteria, which requires findings consistent with sacroiliitis on magnetic resonance imaging (MRI) per ASAS/Outcome Measures in Rheumatology (OMERACT) plus 1 spondyloarthritis (SpA) feature, or the presence of HLA B-27 plus two SpA features [2]. With the availability of MRI, the presence of signals consistent with inflammation in the axial skeleton without visible radiographic changes can be assessed [2-4].

Patients with AS and nr-axSpA have comparable clinical characteristics and burden of disease, requiring similar treatment [5]. Nonsteroidal anti-inflammatory drugs (NSAIDs) are considered first-line therapy for patients with AS and nr-axSpA [6, 7]. Traditional conventional disease-modifying antirheumatic drugs (cDMARDs) such as methotrexate and sulfasalazine are not considered effective for the treatment of axSpA [7-9]. Anti-tumor necrosis factor (TNF) agents (adalimumab, etanercept, golimumab, infliximab, and certolizumab pegol) and interleukin-17 (IL-17) inhibitors (secukinumab and ixekizumab) are Food and Drug Administration (FDA)-approved therapies for patients with AS. Certolizumab pegol was approved for the treatment of nr-axSpA by the FDA in March 2019 and is currently the only approved biologic for nr-axSpA in the United States (US).

The primary goal of treating patients with nr-axSpA is to maximize long-term health-related quality of life (HRQoL) through control of symptoms and inflammation, prevention of progressive structural damage, preservation of function and social participation [7]. This study was conducted to assess levels of biologic use and reasons for switching among patients with nr-axSpA in the US prior to the approval of the first biologic for this indication.

\section{METHODS}

This study employed a cross-sectional survey design, and the survey methodology was implemented as previously described [10]. Rheumatologists in the US that provided consultation for $\geq 10$ axSpA patients per month were eligible to participate and were recruited via publicly available physician lists. A geographically representative sample of eligible rheumatologists $\quad(n=88) \quad$ was achieved. Rheumatologists completed patient record forms which included patient demographic and treatment pattern data for the next five consecutive nr-axSpA patients they consulted with. Data from 495 patient records were provided. Rheumatologists also provided reasons why they prescribed or discontinued a specific medication. For patients records to be included in the survey, patients were required to have a 
rheumatologist-confirmed diagnosis of nraxSpA.

All questionnaires used in the survey were reviewed and approved by Western Institutional Review Board (IRB). Patients provided consent for de-identified and aggregated reporting of research findings. Data were de-identified according to the Health Insurance Portability and Accountability Act (HIPAA) regulations before receipt by Adelphi Real World. Data were collected from June to August 2018.

\section{Clinical Characteristics and Outcome Measures}

Each rheumatologist completed patient record forms which included patient demographics (sex, age, body mass index (BMI), employment status), disease status (defined as improving, stable, unstable, and deteriorating), remission status, clinical characteristics, and current treatment patterns. The physician global assessment was completed by the rheumatologist with a 0 indicating best and a 100 indicating worst possible. Rheumatologists also indicated their reasons for prescribing biologics and their reasons for switching patients to a different biologic.

\section{Statistical Analyses}

Descriptive analyses of patient demographics, clinical characteristics, treatment patterns, and reasons for discontinuation were conducted. Categorical variables were analyzed by frequency counts and percentages, with Chisquare tests used for subgroup analyses. Continuous variables were analyzed by mean [standard deviation (SD)], with two-sample $t$ tests used for subgroup analyses.

\section{RESULTS}

\section{Demographics}

A total of $495 \mathrm{nr}$-axSpA patients were included in this study. Overall, 53.3\% $(n=264)$ of $n r-a x S p A$ patients were male, had a mean age of 44.2 years, mean BMI of 27.1 , and $77.7 \%$ were employed either full-time or part-time (Table 1). Rheumatologists reported that the majority of nr-axSpA patients' current disease status was considered stable or improving (86.5\%), and $40.7 \%$ were in remission. The mean physician's global assessment was 31.1 for nr-axSpA patients.

\section{Medication Use}

More than half $(59.6 \%)$ of nr-axSpA patients were currently receiving a biologic, with $47.4 \%$ receiving adalimumab, followed by etanercept (22.5\%), infliximab (12.1\%), certolizumab pegol (6.9\%), golimumab $(5.5 \%)$, and secukinumab (5.5\%). Overall, $48.1 \%(n=238)$ were receiving a biologic as monotherapy and $11.5 \%(n=57)$ were receiving a biologic in combination with a cDMARD (Table 1). In addition, $18.4 \%(n=91)$ of nr-axSpA patients were receiving a cDMARD without a biologic, $18.2 \%(n=90)$ were receiving a NSAID/ cyclooxygenase- 2 inhibitor (Cox$2)$, and $2.0 \%(n=10)$ were not receiving any type of medication. Of the patients receiving a biologic, the majority $(77.8 \% ; n=224)$ were receiving their first biologic (Fig. 1).

\section{Factors that Influence Choice of a Biologic}

For most patients (92.7\%), rheumatologists reported that strong overall efficacy was one of the main reasons why they prescribed the current biologic to their nr-axSpA patient (Table 2). For over half of patients, rheumatologists also indicated that familiarity with the drug (67.2\%), fast onset of action (55.5\%), inhibiting disease progression $(53.8 \%)$, sustained pain relief $(51.8 \%)$, and good overall safety profile $(50.8 \%)$ were reasons they prescribed current biologics.

\section{Reasons for Switching to a Different Biologic}

Of 295 nr-axSpA patients receiving a biologic, $25.1 \%(n=74)$ were receiving either their second or third biologic. Rheumatologists provided reasons why these patients were switched to a different biologic. The most frequently reported reasons were due to condition 
Table 1 Patient demographics and medication use of $\mathrm{Nr}$ axSpA patients

\begin{tabular}{|c|c|}
\hline & $\begin{array}{l}\mathrm{Nr}-\mathrm{axS} \mathrm{pA} \\
\text { patients } \\
(n=495)\end{array}$ \\
\hline \multicolumn{2}{|l|}{ Sex } \\
\hline Male & $264(53.3 \%)$ \\
\hline Female & $231(46.7 \%)$ \\
\hline Age, mean & 44.2 \\
\hline \multicolumn{2}{|l|}{ Ethnic, origin } \\
\hline White/Caucasian & $394(79.6 \%)$ \\
\hline African American & $34(6.9 \%)$ \\
\hline Native American & $2(0.4 \%)$ \\
\hline Asian & $13(2.6 \%)$ \\
\hline Middle Eastern & $5(1.0 \%)$ \\
\hline Mixed Race & $12(2.4 \%)$ \\
\hline Other & $0(0.0 \%)$ \\
\hline Hispanic/Latino & $35(7.1 \%)$ \\
\hline BMI $\left(\mathrm{kg} / \mathrm{m}^{2}\right)$, mean & 27.1 \\
\hline \multicolumn{2}{|l|}{ Smoking status* } \\
\hline Current smoker & $53(11.6 \%)$ \\
\hline Ex-smoker & $91(19.9 \%)$ \\
\hline Never smoked & $313(68.5 \%)$ \\
\hline \multicolumn{2}{|l|}{ Employment status ${ }^{* *}$} \\
\hline Full-time & $344(69.8 \%)$ \\
\hline Part-time & $39(7.9 \%)$ \\
\hline Homemaker & $37(7.5 \%)$ \\
\hline Student & $14(2.8 \%)$ \\
\hline Unemployed & $20(4.1 \%)$ \\
\hline Retired & $35(7.1 \%)$ \\
\hline Long-term sick leave & $4(0.8 \%)$ \\
\hline \multicolumn{2}{|l|}{ Disease status } \\
\hline Improving & $153(30.9 \%)$ \\
\hline Stable & $275(55.6 \%)$ \\
\hline Unstable & $40(8.1 \%)$ \\
\hline
\end{tabular}

Table 1 continued

\begin{tabular}{ll}
\hline & $\begin{array}{l}\text { Nr-axSpA } \\
\text { patients } \\
(\boldsymbol{n}=\mathbf{4 9 5})\end{array}$ \\
\hline Deteriorating & $27(5.5 \%)$ \\
In remission & $189(40.7 \%)$ \\
Physician's global assessment ${ }^{* * *}$, mean & 31.1 \\
Time since diagnosis, months, mean & 46.2 \\
Medication & \\
Biologic without cDMARD & $238(48.1 \%)$ \\
Biologic and cDMARD & $57(11.5 \%)$ \\
cDMARD & $91(18.4 \%)$ \\
NSAID/Cox-2 & $90(18.2 \%)$ \\
No medication & $10(2.0 \%)$ \\
Duration of current biologic therapy & 20.5 \\
months, mean & \\
\hline *Smoking status: $n=457$ & \\
$* *$ Employment status: $n=493$ & \\
$* * *$ Physician's global assessment: $n=75$ \\
${ }^{* * *}$ Duration of current biologic therapy: $n=307$
\end{tabular}

worsening (51.4\%), followed by secondary lack of efficacy $(48.6 \%)$, lack of alleviation of pain $(27.0 \%)$, and remission not being induced (26.0\%) (Fig. 2). Primary lack of efficacy, remission not being maintained, and patients requesting a change in therapy were each reported for $14.9 \%$ of patients as to why they were being switched to a different biologic.

\section{DISCUSSION}

This study provides real-world evidence on the medication use and the reasons why nr-axSpA patients switch biologic therapy in the US. At the time of the study, over half (59.6\%) of nr-axSpA patients were prescribed biologic therapy even though there was not an FDA-approved biologic for nr-axSpA during the time the study was conducted.

The treatment landscape for $\mathrm{nr}-\mathrm{axSpA}$ has changed with the emergence of biologic agents. NSAIDs are still considered first-line 


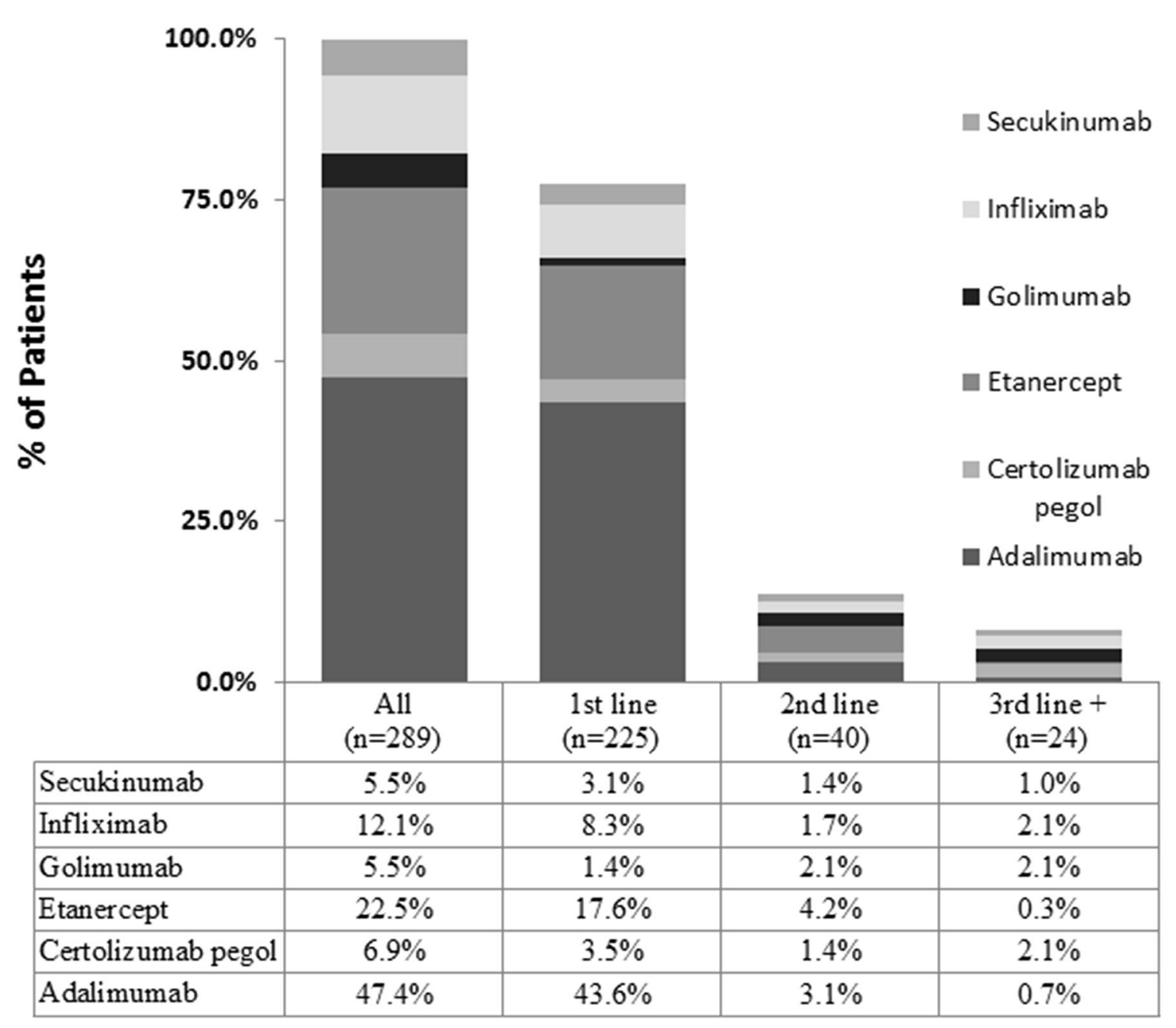

Fig. 1 Line of biologic therapy among $\mathrm{Nr}$-axSpA patients

pharmacological treatment for nr-axSpA [11], however biologics may be effective for patients that do not respond to NSAIDs. Biologics are considered for treating nr-axSpA patients with objective signs of inflammation, defined as active inflammation seen on MRI or elevated C-reactive protein (CRP) levels or patients who do not respond to NSAID therapy [6]. Currently, certolizumab pegol is the only FDA-approved biologic for nr-axSpA in the US. However, agents directed at the IL-17 pathway, such as ixekizumab [12-14] and secukinumab [15-17] have also proven to be effective in both AS and nr-axSpA.

Patient symptoms often drive the initiation and choice of treatment. In this study, we found that in addition to strong overall efficacy and safety, that fast onset of action, sustained pain relief, reduced fatigue, and maintaining the patients' ability to perform daily activities were factors that influenced rheumatologists' treatment choices for their nr-axSpA patients. Lack of alleviation of pain, the condition worsening, and remission not being maintained were also reasons why rheumatologists switch nr-axSpA patients to a different biologic.

Some limitations of this study should be considered. Rheumatologists were required to include patients who had a diagnosis of nraxSpA in their medical records, but this may not necessarily have included patients who fulfilled the formal classification criteria or clinical test results, so misclassification could exist. Additionally, this study does not capture data from 
Table 2 Rheumatologists' reasons for choosing a specific biologic therapy

Reasons for choice, $n(\%)$

$n=299$

Strong overall efficacy

$277(92.6 \%)$

Familiarity/experience with drug

$201(67.2 \%)$

Fast onset of action

$166(55.5 \%)$

Inhibits disease progression

$161(53.8 \%)$

Sustained pain relief

$155(51.8 \%)$

Good overall safety profile

$152(50.8 \%)$

Achieves low disease activity

$144(48.2 \%)$

Efficacious in treating joint symptoms

$139(46.5 \%)$

Convincing efficacy data in clinical trials

$133(44.5 \%)$

Maintains patients' ability to perform daily tasks/activities

$129(43.1 \%)$

Achieves clinical remission

$128(42.8 \%)$

Control of acute episode/flares

$123(41.1 \%)$

Included in local/national formulary

$122(40.8 \%)$

Strong efficacy as monotherapy

$112(37.5 \%)$

Achieves consistent efficacy over time

$106(35.5 \%)$

Reduces fatigue

$97(32.4 \%)$

Has a reasonable cost-effectiveness ratio

$76(25.4 \%)$

Method of delivery is acceptable to the patient

$76(25.4 \%)$

Allows reduction in steroid use

$75(25.1 \%)$

Improves patients' mood/outlook

$72(24.1 \%)$

Low out of pocket cost/affordability for patients

$71(23.7 \%)$

Specifically to address enthesitis

$58(19.4 \%)$

Delays onset of SI joint involvement

$58(19.4 \%)$

Delays or prevents the progression of the condition to AS/radiographic disease

$53(17.7 \%)$

Suitability for patients with CV risk

$29(9.7 \%)$

No black box warning concerns

$10(3.3 \%)$

patients who are not under the care of a rheumatologist. Drug unresponsiveness and disease status was determined by the rheumatologist and we did not collect information regarding which parameters were used to make these clinical decisions. Despite these limitations, this study provides a pragmatic overview of real-world treatment patterns of consulting
nr-axSpA patients in the United States prior to the FDA approval of a biologic treatment for nraxSpA patients. These analyses also provide insight into the factors that impact biologic choice and biologic switching among rheumatologists in the United States. 


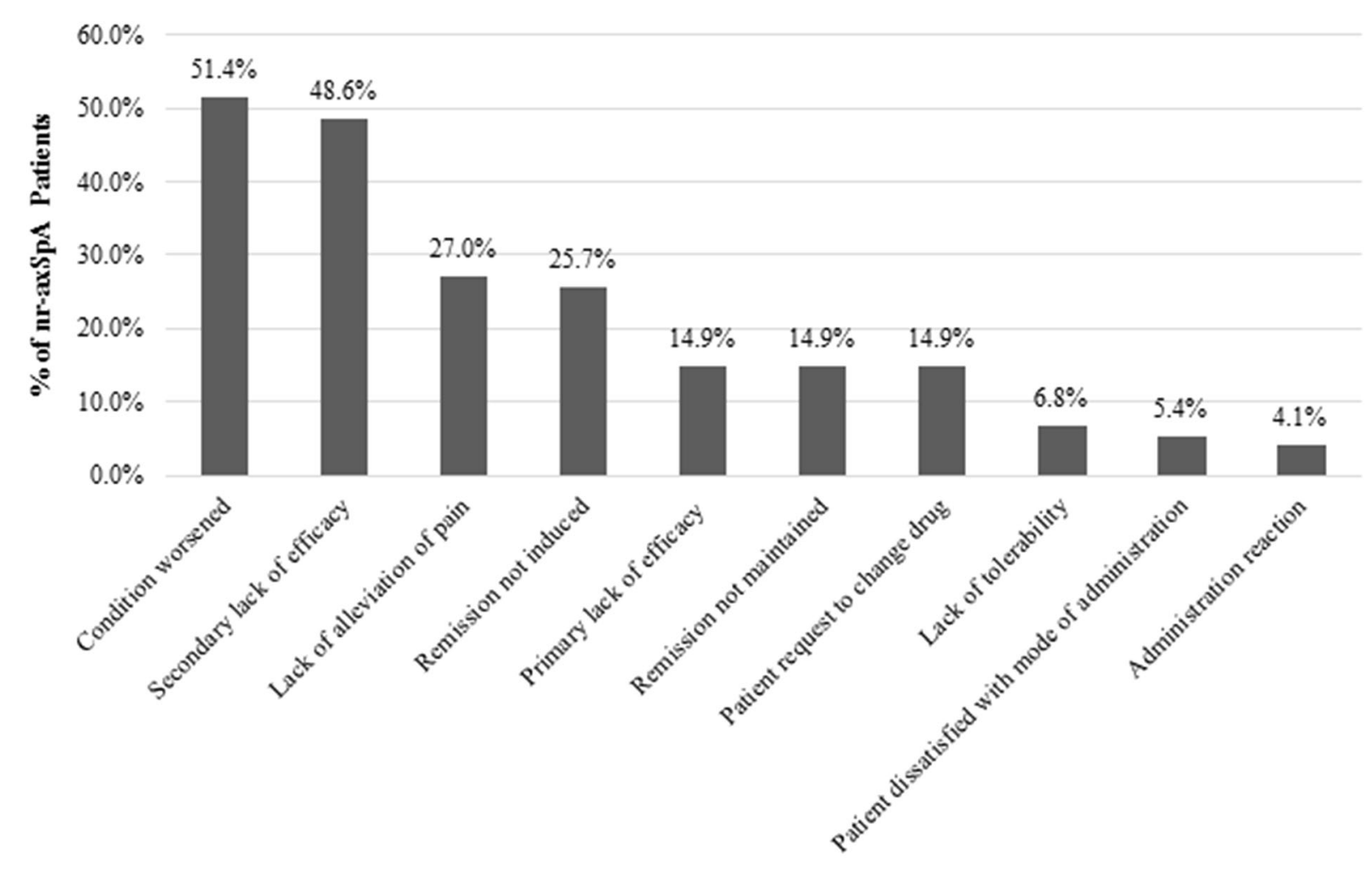

Reasons for Switching to a Different Biologic

Fig. 2 Top ten reasons that rheumatologists switched $\mathrm{Nr}$-axSpA patients to a different biologic $(n=74)$

\section{CONCLUSIONS}

This study suggests that around 60\% of nraxSpA patients were receiving biologic therapy prior to the approval of certolizumab pegol. Switching of biologics is frequent in nr-axSpA patients and is usually due to lack of efficacy, loss or response, and effort to accomplish remission.

\section{ACKNOWLEDGEMENTS}

We would like to thank all the rheumatologists and patients that participated in this study.

Funding. Sponsorship for this study the Rapid Service Fee were funded by Eli Lilly and Company. All authors had full access to all the data in this study and take complete responsibility for the integrity of the data and accuracy of the data analysis.

Authorship. All named authors meet the International Committee of Medical Journal Editors (ICMJE) criteria for authorship for this article, take responsibility for the integrity of the work as a whole, and have given their approval for this version to be published.

Disclosures. Atul Deodhar is an employee of Oregon Health and Science University. Atul Deodhar has received consulting/advisory board fees from AbbVie, Amgen, Boehringer Ingelheim, Celgene, Eli Lilly, Galapagos, GlaxoSmithKline, Janssen, Novartis, Pfizer, and UCB. Atul Deodhar has also received research grants from AbbVie, Eli Lilly, GlaxoSmithKline, Novartis, Pfizer, and UCB. Theresa Hunter and David Sandoval are employees and shareholders of Eli Lilly and Company. Nicola Booth and 
Elizabeth Holdsworth are employees of Adelphi Real World.

Compliance with Ethics Guidelines. All questionnaires used in the survey were reviewed and approved by Western Institutional Review Board (IRB). Patients provided consent for deidentified and aggregated reporting of research findings. Data were de-identified according to the Health Insurance Portability and Accountability Act (HIPAA) regulations before receipt by Adelphi Real World.

Data Availability. The datasets generated during and/or analyzed during the current study are available from the corresponding author on reasonable request.

Open Access. This article is licensed under a Creative Commons Attribution-NonCommercial 4.0 International License, which permits any non-commercial use, sharing, adaptation, distribution and reproduction in any medium or format, as long as you give appropriate credit to the original author(s) and the source, provide a link to the Creative Commons licence, and indicate if changes were made. The images or other third party material in this article are included in the article's Creative Commons licence, unless indicated otherwise in a credit line to the material. If material is not included in the article's Creative Commons licence and your intended use is not permitted by statutory regulation or exceeds the permitted use, you will need to obtain permission directly from the copyright holder. To view a copy of this licence, visit http:// creativecommons.org/licenses/by-nc/4.0/.

\section{REFERENCES}

1. van der Linden S, Valkenburg HA, Cats A. Evaluation of diagnostic criteria for ankylosing spondylitis. A proposal for modification of the New York criteria. Arthritis Rheum. 1984;27:361-8.

2. Rudwaleit M, van der Heijde D, Landewe R, et al. The development of assessment of Spondyloarthritis International Society classification criteria for axial spondyloarthritis (part II): validation and final selection. Ann Rheum Dis. 2009;68:777-83.
3. Barkham N, Marzo-Ortega H, McGonagle D, et al. How to diagnose axial spondyloarthropathy early. Ann Rheum Dis. 2004;63:471-2.

4. Weber U, Lambert R, Ostergaard M, et al. The diagnostic utility of magnetic resonance imaging in spondyloarthritis: an international multicenter evaluation of one hundred eighty-seven subjects. Arthritis Rheum. 2010;62:3048-58.

5. Rudwaleit M, Haibel H, Baraliakos X, et al. The early disease stage in axial spondyloarthritis: results from the German spondyloarthritis inception cohort. Arthritis Rheum. 2009;60:717-27.

6. Ward M, Deodhar A, Gensler LS, et al. Update of the American College of Rheumatology/Spondylitis Association of America/Spondyloarthritis Research and Treatment Network Recommendations for the treatment of ankylosing spondylitis and nonradiographic axial spondyloarthritis. Arthritis Rheumatol. $2019 ; 71: 1599-613$.

7. van der Heijde D, Ramiro S, Landewe R, et al. 2016 Update to the ASAS-EULAR management recommendations for axial spondyloarthritis. Ann Rheum Dis. 2017;76:978-91.

8. Dougados $\mathrm{M}$, vam der Linden $\mathrm{S}$, Leirisalo-Repo $\mathrm{M}$, et al. Sulphasalazine in the treatment of spondyloarthropathy. A randomized, multicenter, doubleblind, placebo-controlled study. Arthritis Rheum. 1995;38(618):27.

9. Braun J, Zochling J, Baraliakos X, et al. Efficacy of sulfasalazine in patients with inflammatory back pain due to undifferentiated spondyloarthritis and early AS; multicenter randomised controlled trial. Ann Rheum Dis. 2006;65:1145-53.

10. Anderson P, Benford M, Harris N, Karavali M, Piercy J. Real world physician and patient behavior across countries: disease-specific programmes-a means to understand. Curr Med Res Opin. 2008;24:3063-72.

11. Ghosh N, Ruderman EM. Nonradiographic axial spondyloarthritis: clinical and therapeutic relevance. Arthritis Res Ther. 2017;19:286.

12. Deodhar A, Poddubnyy D, Pacheco-Tena C, et al. Efficacy and safety of ixekizumab in the treatment of radiographic axial spondyloarthritis: sixteenweek results from a phase III randomized, doubleblind, placebo-controlled trial in patients with prior inadequate response to or intolerance of tumor necrosis factor inhibitors. Arthritis Rheumatol. 2019;71(4):599-611.

13. Deodhar A, van der Heijde D, Gensler LS, et al. Ixekizumab for patients with non-radiographic axial spondyloarthritis (COAST-X): a randomised, 
placebo-controlled trial. Lancet (Lond Engl). 2020;395(10217):53-64.

14. van der Heijde D, Cheng-Chung Wei J, Dougados $\mathrm{M}$, et al. Ixekizumab, an interleukin-17A antagonist in the treatment of ankylosing spondylitis or radiographic axial spondyloarthritis in patients previously untreated with biological disease-modifying anti-rheumatic drugs (COAST-V): 16-week results of a phase 3 randomised, double-blind, active-controlled and placebo-controlled trial. Int J Rheum Dis. 2018;392:2441-51.

15. Baeten D, Sieper J, Braun J, et al. Secukinumab, an interleukin-17A inhibitor, in ankylosing spondylitis. N Engl Med. 2015;373:2534-48.
16. Pavelka K, Kivitz A, Dokoupilvova E, et al. Efficacy, safety, and tolerability of secukinumab in patients with active ankylosing spondylitis: a randomized, double-blind phase 3 study, MEASURE 3. Arthritis Res Ther. 2017;19:285.

17. Deodhar A, Blanco R, Dokoupilova E, et al. Secukinumab $150 \mathrm{mg}$ significantly improves signs and symptoms of non-radiographic axial spondyloarthritis: results from a Phase 3 double-blind, randomized, placebo-controlled study. Arthritis Rheumatol. 2019;71(455 suppl 10) (Abstract L21). 